\title{
Stress-strain state of concrete filled steel tubular columns of annular cross-section taking into account physical nonlinearity
}

\author{
Kazbek Khashkhozhev ${ }^{1}$, Anton Chepurnenko ${ }^{2 *}$, Tatyana Polyakova ${ }^{2}$, Marina Grigoryan ${ }^{2}$, \\ and Batyr Yazyev $^{2}$ \\ ${ }^{1}$ Kabardino-Balkarian State University named after Kh.M. Berbekov, 360004, Nalchik, Russia \\ ${ }^{2}$ Don State Technical University, 344002, Rostov-on-Don, Russia
}

\begin{abstract}
The article presents the derivation of the resolving equations for calculating concrete filled steel tubular columns with an annular crosssection under central compression, taking into account physical nonlinearity. The solution is performed numerically by the finite difference method. The deformation theory of plasticity of concrete by G.A. Geniev is used as the law of deformation
\end{abstract}

\section{Introduction}

Compared to traditional reinforced concrete elements, concrete filled steel tubular (CFST) columns have a number of significant advantages, but at the same time they also have disadvantages, one of which is the lack of a generally accepted methods for calculating the bearing capacity of CFST columns taking into account the effect of lateral compression of concrete. Another significant disadvantage of CFST columns is the violation of joint operation in the transverse direction between concrete and a steel shell in the elastic stage due to the higher Poisson's ratio of steel. To eliminate this disadvantage, lateral compression prestresses are created in the concrete core. These circumstances should be reflected in the calculation model.

To ensure the joint operation of steel shell with concrete at the early stages of loading, A.L. Krishan proposed to perform a preliminary compression of the concrete core by longterm pressing of the concrete mixture using a specially designed void former, or by successively pressing three steel tubes of different diameters into the concrete mixture along a guide rod located coaxially with the outer shell [1]. In this case, the column acquires an annular section. The papers [1-5] present methods for calculating such columns, but they contain empirical coefficients, which limits the possibility of their application for new concrete compositions, other materials of shell, etc.

The purpose of this work is to construct a model of CFST column deformation based on the most general equations of the mechanics of a deformable solid, free of empirical coefficients.

\footnotetext{
* Corresponding author: anton_chepurnenk@mail.ru
} 


\section{Methods}

The element of the considered structure is shown in Fig. 1.

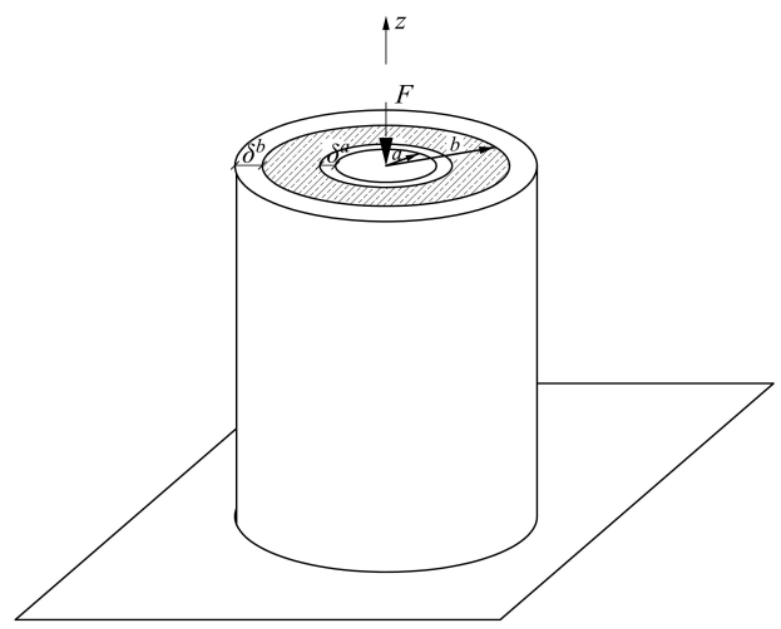

Fig. 1. Calculation scheme

Hoop stresses in the inner and outer shell can be calculated using the formulas:

$$
\sigma_{s \theta}^{a}=-\frac{p_{a} a}{\delta^{a}} ; \sigma_{s \theta}^{b}=\frac{p_{b} b}{\delta^{b}},
$$

where $a$ and $b$ are the inner and outer radius of the concrete core, respectively, $p_{\mathrm{a}}$ and $p_{\mathrm{b}}$ are the inner and outer contact pressure $\left(p_{a}=-\sigma_{r}(a), p_{b}=-\sigma_{r}(b)\right), \delta^{a}$ and $\delta^{b}-$ thickness of the inner and outer steel shell.

When deriving the resolving equations, we will take into account the presence of creep deformations. The relationship between stresses and strains in concrete is written as:

$$
\begin{aligned}
& \varepsilon_{\theta}=\frac{1}{E}\left(\sigma_{\theta}-v\left(\sigma_{r}+\sigma_{z}\right)\right)+\varepsilon_{\theta}^{*} ; \\
& \varepsilon_{r}=\frac{1}{E}\left(\sigma_{r}-v\left(\sigma_{\theta}+\sigma_{z}\right)\right)+\varepsilon_{r}^{*} ; \\
& \varepsilon_{z}=\frac{1}{E}\left(\sigma_{z}-v\left(\sigma_{\theta}+\sigma_{r}\right)\right)+\varepsilon_{z}^{*},
\end{aligned}
$$

where $\varepsilon_{\theta}^{*}, \varepsilon_{r}^{*}, \varepsilon_{z}^{*}$ - creep strains.

When deriving the basic equation, we will assume that the modulus of elasticity of concrete is a function of $r$. Concrete core is in the conditions of an axisymmetric problem, for which the following differential dependencies are valid $[6,7]$ :

$$
\varepsilon_{\theta}^{\prime}+\frac{\varepsilon_{\theta}-\varepsilon_{r}}{r}=0 ; \quad \sigma_{r}^{\prime}+\frac{\sigma_{r}-\sigma_{\theta}}{r}=0
$$

The dash in formulas (3) denotes the derivative with respect to the radius.

We express the stress $\sigma_{z}$ from (3): 


$$
\sigma_{z}=v\left(\sigma_{\theta}+\sigma_{r}\right)+E\left(\varepsilon_{z}-\varepsilon_{z}^{*}\right)
$$

Let us further differentiate equality (4) with respect to $r$ :

$$
\sigma_{z}^{\prime}=v\left(\sigma_{\theta}^{\prime}+\sigma_{r}^{\prime}\right)-\left(E \varepsilon_{z}^{*}\right)^{\prime}+E^{\prime} \varepsilon_{z}+E \varepsilon_{z}^{\prime}
$$

We will assume that all points of the column end section move in the same way, i.e. deformation $\varepsilon_{\mathrm{z}}$ does not depend on $r$. Then equality (5) can be rewritten as:

$$
\sigma_{z}^{\prime}=v\left(\sigma_{\theta}^{\prime}+\sigma_{r}^{\prime}\right)-\left(E \varepsilon_{z}^{*}\right)^{\prime}+E^{\prime} \varepsilon_{z}
$$

We express the stress $\sigma_{\theta}$ from (3):

$$
\sigma_{\theta}=r \sigma_{r}^{\prime}+\sigma_{r}
$$

Let us further substitute (7) into (5):

$$
\sigma_{z}^{\prime}=v\left(r \sigma_{r}^{\prime \prime}+3 \sigma_{r}^{\prime}\right)-\left(E \varepsilon_{z}^{*}\right)^{\prime}+E^{\prime} \varepsilon_{z}
$$

Substituting the first equation from (2) into the first equation from (3) taking into account (4) - (8), we obtain:

$$
\sigma_{r}^{\prime \prime}+\left(\frac{3}{r}-\frac{E^{\prime}}{E}\right) \sigma_{r}^{\prime}-\sigma_{r} \frac{1-2 v}{E r(1-v)} E^{\prime}=-\frac{E}{\left(1-v^{2}\right) r}\left(\left(\varepsilon_{\theta}^{*}\right)^{\prime}+\frac{\varepsilon_{\theta}^{*}-\varepsilon_{r}^{*}}{r}+v\left(\varepsilon_{z}^{*}\right)^{\prime}\right) .
$$

The resulting equation coincides with the main resolving equation for the case of a plane deformed state of the cylinder [8]. Equation (9) is solved numerically by the finite difference method. Let's rewrite this equation as:

where

$$
\sigma_{r}^{\prime \prime}+\varphi(r) \sigma_{r}^{\prime}+\psi(r) \sigma_{r}=f(r)
$$

$$
\varphi(r)=\left(\frac{3}{r}-\frac{E^{\prime}}{E}\right), \psi(r)=-\frac{1-2 v}{E r(1-v)} E^{\prime}, f(r)=-\frac{E}{\left(1-v^{2}\right) r}\left(\left(\varepsilon_{\theta}^{*}\right)^{\prime}+\frac{\varepsilon_{\theta}^{*}-\varepsilon_{r}^{*}}{r}+v\left(\varepsilon_{z}^{*}\right)^{\prime}\right) .
$$

The interval from $a$ to $b$ is divided into $\mathrm{n}$ segments. Difference approximation of equation (10) for nodes with $i=2 \ldots n$ is written in the form:

$$
\frac{\sigma_{i+1}-2 \sigma_{i}+\sigma_{i-1}}{\Delta r^{2}}+\varphi\left(r_{i}\right) \frac{\sigma_{i+1}-\sigma_{i-1}}{2 \Delta r}+\psi\left(r_{i}\right) \sigma_{i}=f\left(r_{i}\right) .
$$

As a result, we have $n-1$ linear equations with $n+1$ unknowns. To these equations it is necessary to add conditions on the inner and outer surfaces of the concrete core, which are 
the equality of the annular deformations of concrete and steel. Taking into account (4), we represent the tangential deformation of concrete in the following form:

$$
\varepsilon_{\theta}=\frac{1}{E_{1}}\left(\sigma_{\theta}-v_{1} \sigma_{r}\right)+\varepsilon_{\theta}^{*}+v \varepsilon_{z}^{*}-v \varepsilon_{z}
$$

where $E_{1}=\frac{E}{1-v^{2}} ; v_{1}=\frac{v}{1-v}$.

Equating (12) to the annular deformations of the pipe, taking into account (7), for $r=a$ we obtain the following condition:

$$
\frac{1}{E_{1}}\left(a \sigma_{r}^{\prime}+\sigma_{r}\left(1-v_{1}\right)\right)+\varepsilon_{\theta}^{*}+v \varepsilon_{z}^{*}-v \varepsilon_{z}=\frac{1}{E_{s}^{a}}\left(-\frac{p_{a} a}{\delta^{a}}-v_{s}^{a} \sigma_{s z}^{a}\right)
$$

where $E_{s}^{a}$ and $v_{s}^{a}$ are respectively, the modulus of elasticity and Poisson's ratio of the inner tube.

For $r=b$ the condition is written in the same way:

$$
\frac{1}{E_{1}}\left(b \sigma_{r}^{\prime}+\sigma_{r}\left(1-v_{1}\right)\right)+\varepsilon_{\theta}^{*}+v \varepsilon_{z}^{*}-v \varepsilon_{z}=\frac{1}{E_{s}^{b}}\left(\frac{p_{b} b}{\delta^{b}}-v_{s}^{b} \sigma_{s z}^{b}\right)
$$

Conditions (13) and (14) contain 3 additional unknowns: deformation $\varepsilon_{\mathrm{z}}$ and stresses $\sigma_{s z}^{a}, \sigma_{s z}^{b}$; therefore, 3 more equations are needed to solve the problem. The first two equations are the conditions for the compatibility of the deformations of concrete and steel tubes along $z$ :

$$
\varepsilon_{z}=\varepsilon_{s z}^{a}=\frac{1}{E_{s}^{a}}\left(\sigma_{s z}^{a}+v_{s}^{a} \frac{p_{a} a}{\delta^{a}}\right) ; \varepsilon_{z}=\varepsilon_{s z}^{b}=\frac{1}{E_{s}^{b}}\left(\sigma_{s z}^{b}-v_{s}^{b} \frac{p_{b} b}{\delta^{b}}\right)
$$

The third equation can be obtained from the condition that the compressive force $\mathrm{F}$ represents the sum of the forces perceived by the concrete and steel shells:

$$
F=F_{b}+F_{s}^{a}+F_{s}^{b}
$$

The forces perceived by the inner and outer tube are calculated as:

$$
F_{s}^{a}=-\sigma_{s z}^{a} A_{s}^{a}, F_{s}^{b}=-\sigma_{s z}^{b} A_{s}^{b}
$$

where $A_{s}^{a}=2 \pi a \delta^{a}, \quad A_{s}^{b}=2 \pi b \delta^{b}$.

The force perceived by the concrete is determined as follows:

$$
F_{b}=-2 \pi \int_{a}^{b} \sigma_{z} r d r=-2 \pi v\left(b^{2} \sigma_{r}(b)-a^{2} \sigma_{r}(a)\right)-\varepsilon_{z} \cdot 2 \pi \int_{a}^{b} E(r) r d r+2 \pi \int_{a}^{b} \varepsilon_{z}^{*} r d r
$$

Thus, when the interval $[a ; b]$ is divided into $n$ segments, the problem is reduced to $n+4$ linear algebraic equations with $n+4$ unknowns. 


\section{Results and Discussion}

The calculation for the short-term action of the load was carried out with the following initial data: $a=0.05 \mathrm{~m}, b=0.15 \mathrm{~m}, \delta^{\mathrm{a}}=\delta^{\mathrm{b}}=1 \mathrm{~mm}$, initial modulus of elasticity of concrete $E_{\mathrm{b} 0}=3.25 \cdot 10^{4} \mathrm{MPa}$, compressive strength of concrete $R_{\mathrm{b}}=22 \mathrm{MPa}$, tensile strength of concrete $R_{\mathrm{bt}}=1.8 \mathrm{MPa}$, steel yield strength $R_{\mathrm{s}}=400 \mathrm{MPa}$. The equations of the deformation theory of plasticity of concrete by G.A. Geniev [9] were used as dependencies that establish a relationship between stresses and instantaneous deformations of concrete, which can also be found in the previous work of the authors [10].

The graph of axial deformation versus load is shown in fig. 2. The ultimate load in this case was $1975 \mathrm{kN}$. The dashed line in fig. 2 shows the solution without taking into account the transverse deformations of concrete and steel cage, which gives the value $F_{\text {ult }}=$ $1610 \mathrm{kN}$.

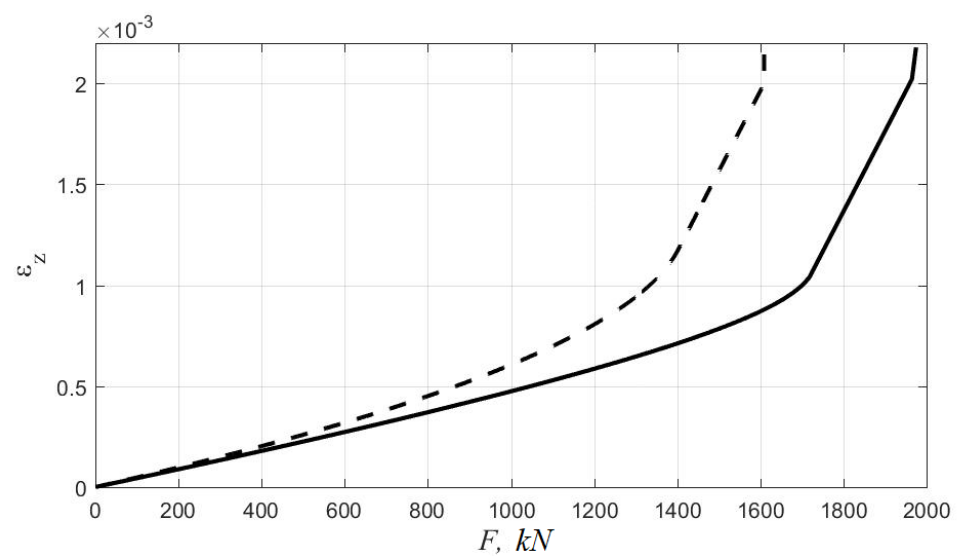

Fig. 2. Dependence of the axial deformation of the column on the load

The contact pressure between the inner shell and concrete at low load levels is positive and then becomes negative. Between the outer shell and the core, on the contrary, at low loads, it is negative, and then becomes positive. Graphs of changes in $p_{\mathrm{a}}$ and $p_{\mathrm{b}}$ depending on the compressive force are shown in figure 3.

The joint work of steel shells with concrete at the early stages of loading can be provided by creating a preliminary compression of the concrete core. In addition to ensuring the compatibility of the transverse deformations of concrete and steel, precompression leads to an increase in the bearing capacity of the columns due to their operation under conditions of the volumetric stress state and the denser concrete structure. Fig. 4 shows the graphs of changes in axial deformation depending on the magnitude of the compressive force at different levels of pre-compression, calcaluted with the same initial data as before. At a level of $p_{0}=3 \mathrm{MPa}$, as compared to the column with an uncompressed core, the increase in bearing capacity only due to the work of concrete under conditions of triaxial compression was $26.6 \%$. 


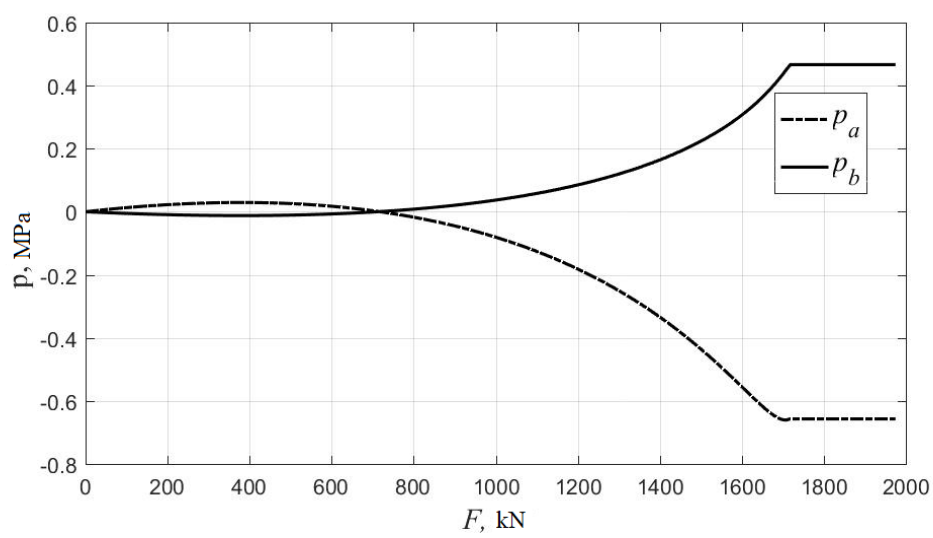

Fig. 3. Change in contact pressures depending on the magnitude of the load

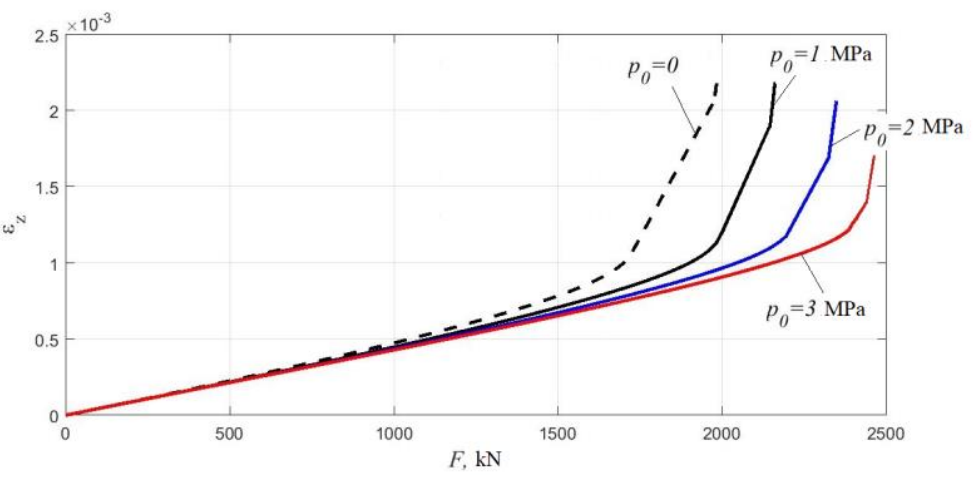

Fig. 4. Change in axial deformation depending on the load at different levels of pre-compression

\section{Conclusions}

A model of deformation of concrete filled steel tubular columns of annular cross-section under central compression is constructed, taking into account physical nonlinearity and creep. The calculation problem is reduced to a second-order differential equation. It was found that the contact pressure between the inner shell and concrete at low load levels is positive and then becomes negative. Between the outer shell and the core, on the contrary, at low loads, it is negative, and then becomes positive. The need to create preliminary compressive stresses in the concrete core has been confirmed by numerical modeling. In this case, only due to the work of concrete under conditions of volumetric stress state, the increase in bearing capacity was $26.6 \%$.

\section{References}

1. A. Krishan, V. Rimshin, E. Troshkina, IOP Conf. Ser.: Mater. Sci. Eng. 463, 022062 (2018)

2. A. Krishan, E. Troshkina, E. Chernyshova, IFAC-PapersOnLine 51, 150-154 (2018)

3. A. Krishan, E. Chernyshova, R. Sabirov, Procedia Engineering 150, 1878-1884 (2016)

4. Y. Wong et al, Composites Part B: Engineering 39, 451-466 (2008) 
5. C. Wan, X. Zha, Steel and Composite Structures 20, 571-597 (2016)

6. S. Litvinov, L. Trush, S. Yazyev, Materials Science Forum 935, 121-126 (2018)

7. L. Trush et al, Energy Management of Municipal Transportation Facilities and Transport, 885-893 (2017)

8. S. Yazyev et al, Key Engineering Materials 869, 209-217 (2020)

9. G. Geniev, V. Kissuk, G. Tupin, Theory of plasticity of concrete and reinforced concrete (Stroyizdat, Moscow, 1974)

10. M. Grigoryan et al, IOP Conf. Ser.: Mater. Sci. Eng. 913, 022069 (2020) 